Article

\title{
Newsworthiness and the Public's Response in Russian Social Media: A Comparison of State and Private News Organizations
}

\author{
Darja Judina * and Konstantin Platonov \\ d.yudina@spbu.ru (D.J.); k.platonov@spbu.ru (K.P.) \\ * Corresponding author \\ Submitted: 14 December 2018 | Accepted: 22 April 2019 | Published: 9 August 2019
}

Center for Sociological and Internet Research, Saint Petersburg State University, 191124 Saint-Petersburg, Russia; E-Mails:

\begin{abstract}
Social media have become one of the most important news delivery channels due to their interactivity and large audiences. The content published by news organizations on social networking sites is of particular value to sociologists, because it allows measurement of users' attitude to certain events. However, we understand that the media choose which events become news in accordance with certain criteria, such as news values. In this study, we decided to examine how news values determine the public's response as expressed by likes, reposts, and comments. To analyze the characteristics of different media and their audiences, we selected four popular newsgroups on the social networking site Vkontakte: TASS and Russia Today, representing the state media, alongside RBC and Meduza, representing the private media. The posts of the selected newsgroups were coded and analyzed by means of Harcup and O'Neill taxonomy of values (2016). The study showed that news organizations tend to have preferences for some news values rather than others. Regression analysis revealed positive relationships between 1) the sharing of likes and good and entertaining content, 2) the sharing of comments and the presence of celebrities or conflicts in news, 3) the sharing of reposts and comments and significant events. An unexpected discovery was a negative dependency between the number of comments and the presence of exclusive content.
\end{abstract}

\section{Keywords}

audience; media agenda; news organizations; news values; newsworthiness; Russia; social media; social networks

Issue

This article is part of the issue "Public Discussion in Russian Social Media", edited by Olessia Koltsova (Higher School of Economics, Russia) and Svetlana Bodrunova (St. Petersburg State University, Russia).

(C) 2019 by the authors; licensee Cogitatio (Lisbon, Portugal). This article is licensed under a Creative Commons Attribution 4.0 International License (CC BY).

\section{Introduction}

The assessment of attributes pertaining to the audiences of online media is an important measurement of public opinion on social media since these news sources contain a significant part of opinions on broadcast news. Social networking sites provide researchers with the opportunity to reveal the socio-demographic characteristics of users as well as their interests and friendships. Applying these parameters, it is possible (in part) to assess the user's political views or his/her prioritized values (DiGrazia, McKelvey, Bollen, \& Rojas, 2013; Preoțiuc-
Pietro, Liu, Hopkins, \& Ungar, 2017). But this analysis is rather complicated, and it does not always provide sufficiently reliable results (Cohen \& Ruths, 2013; Mislove, Lehmann, Ahn, Onnela, \& Rosenquist, 2011). In addition, both the administration of social networking sites and users themselves restrict, for a number of reasons, access to users' personal data, which further undermines the validity of analysis.

In view of these findings, it seems reasonable to try some other approaches in order to analyze the characteristics of the audience of newsgroups. In our previous study, we applied the agenda-setting theory, assuming 
that privately owned, state-independent media adapt news topics to the interest of their own audience, unlike state-owned online media outlets. However, our assumption was not confirmed (Judina \& Platonov, 2018). Nevertheless, we decided to continue exploring the relationship between the content of the news stream and the users' response to it in social media. In this work, we used a journalistic approach to analyzing the content of the news agenda, matching each news item with its corresponding set of news values.

This approach was chosen, firstly, due to our intention to look at the news through the eyes of those who select it. Although some researchers believe that one should watch, not for newsworthiness ( $\varnothing$ rmen, 2018), but for noteworthiness (Lee \& Chyi, 2014) or shareworthiness (Trilling, Tolochko, \& Burscher, 2017) when studying the news agenda in social media, but so far online media with large audiences remain the main daily news sources for a significant proportion (VCIOM, 2018), if not the majority, of users, so we need to understand their reasoning in setting the agenda.

The second reason to choose the concept of newsworthiness was our assumption that the news values which receive the greatest public response demonstrate the preferences of the media audience. In this sense, values reflect not only the policy of media but also characterize the readers themselves, enabling us to understand whether there is an agreement between the audience's interests and the media organization.

We also continue exploring the differences between state and private-owned newsgroups. The contemporary Russian news media environment is characterized by high competition for audience share. Current research shows that $m$ Russian news media adhere to pro-active agenda-building (Hanitzsch, Folker, \& Corinna, 2016) and framing used to legitimize the power (Lukyanova, 2018). Recently, even private-owned media have been charged with politicization (Field et al., 2018). We assume that, in this situation, the increasing ideological polarization between state-owned and private-owned media may lead to the fact that audiences have different, and sometimes diametrically opposed, ideas about the same events. We believe that the theory of news values will highlight additional features of the divergence between these types of media.

\section{Theoretical Framework}

Conceptually, news values are the set of criteria which determine whether a story will become news (Galtung \& Ruge, 1965). On the one hand, it is a theory that explains the principles for selecting events and their attributes, on the other-it is a kind of standard, a tool that simplifies the "production of news": news values "are the terse shorthand references to shared understandings about the nature and purpose of news which can be used to ease the rapid and difficult manufacture of bulletins and news programmes" (Golding \& Elliott, 1979).
The representations of newsworthiness largely depend on the traditions, culture, technology, and economic sphere of society (Dominick, 1993). Among other factors, since the 1960s, the approaches to the classification of news values have flexibly changed in accordance with the development of news genres and content options. The integration of the news flow into social media feeds has expanded the opportunities to analyze feedback and engagement mechanisms.

Above all, as the media market is becoming increasingly competitive, news organizations are trying to bring their content to a wider audience, so they are forced to focus on "infotainment" to varying degrees. (Reinemann, Stanyer, Scherr, \& Legnante, 2012). Therefore, in the 21st century, the existing set of news values was supplemented due to the increased relevance of such news values as conflict, emotions, and visualness (McGregor, 2002).

There is a limited number of articles in which the conception of news values is employed to study news organizations' outlets in social media from the comparative perspective. Several studies, based on data from Facebook and Twitter, show differences in media from different countries (Al-Rawi, 2017), between federal and regional media (Armstrong \& Gao, 2010), as well as those that target traditional and online audiences (García-Perdomo, Salaverría, Kilgo, \& Harlow, 2018).

For our study, we chose the updated taxonomy of news values developed by Harcup and O'Neill (2016), as it was specially adapted to the circumstances of news consumption in social media, taking into account, for example, the presence of audio-visual content in online publications. Since social media provide an opportunity for users to respond to content, including news stories in post layout, the focus of media research is gradually shifting from categories of popularity and exposure to quantitative indicators of involvement, such as user engagement metrics (Ksiazek, Peer, \& Lessard, 2016). The feedback functionality provided by social networking sites may vary slightly, but as a rule, comments, likes, and reposts are present everywhere in one form or another.

The dependencies between these indicators and the characteristics of the content consumed by users have already been studied both in the context of the news and outside it. Almgren and Olsson (2015) demonstrated that users prefer to comment on hard news (for example, news covering changes in "proximity space, politics, and health care"), even if the news site's policy is such that users are encouraged to comment on soft news (Almgren \& Olsson, 2015). Comparative analysis of various user interactions with news posts on Facebook shows that the prevalence of Emoji reactions to the post (instead of simple likes) generally reduces the level of commenting and the intensity of reposting (Smoliarova, Gromova, \& Pavlushkina, 2018). In the study of communication on Instagram, it was found that the intensity of liking could be influenced, for example, by factors such as the presence of people in a photo. Ziegele, Breiner and Quiring (2014), 
using a series of interviews and content analysis of comments, have shown that uncertainty, controversy, comprehensibility, negativity, and personalization contained in news, have influenced the amount of discussion in comments (Ziegele et al., 2014). The tests of predictive models show that sometimes the cause of a large number of comments to the news may not be a news item itself, but particular comments which have sparked a discussion (Tsagkias, Weerkamp, \& De Rijke, 2009). Using the example of retweets (similar to a repost on Twitter), a number of studies have shown that tweets with more emotional content are more likely to be disseminated by users (Hansen, Arvidsson, Nielsen, Colleoni, \& Etter, 2011; Stieglitz \& Dang-Xuan, 2013). Having analyzed the results of the news consumption survey, Lee and $\mathrm{Ma}$ (2012) found no connection between the presence of entertainment in a message and the desire to share it. However, they discovered that this behaviour is significantly influenced by one's prior social media sharing experience (Lee \& Ma, 2012). Qualitative research has revealed that some people may consciously limit themselves when liking and sharing news for privacy reasons (Costera Meijer \& Kormelink, 2015).

\section{Research Questions}

In our research, the basic assumption is that the theory of news values, being a theoretical model explaining the selection of news into an agenda, can be used to detect differences in the types mentioned above and the magnitude of the public's response in social media. Conversely, this model is not applicable to the study of audiences' behaviour. Therefore, the first research question of the article is as follows:

RQ1. How do various news values influence the level of the public's response, expressed in likes, reposts, and comments?

Since we continue to compare various media by their agenda and try to identify differences in behaviour between their audiences, the following two questions relate to the opposition of state- and private-owned media:

RQ2. Are there any differences in the share of news values between state and private newsgroups in social media?

RQ3. Are there any differences in audiences of state and private newsgroups in social media regarding their response rate, expressed in likes, reposts, and comments?

\section{Data}

\subsection{Social Networking Site}

The most visited social networking site in Russia is Vkontakte (vk.com; Live Internet, n.d.), with more than
500 million accounts registered at the time of writing the article. (Vkontakte, n.d.-a). In addition, this platform provides open access to public pages through the API. Therefore, this site was used as a source of data for this study.

\subsection{Newsgroups}

The sample of newsgroups available for analysis includes the four most popular text-oriented media newsgroups in Vkontakte ( 2 state-owned and 2 privately-owned). The procedure of group selection has been described in detail in our previous study (Judina \& Platonov, 2018).

The state media newsgroups selected were TASS (Vkontakte, n.d.-e) and Russia today (Vkontakte, n.d.-d). TASS is the oldest news agency in Russia founded in 1902, comparable in scale to Reuters and the Associated Press, with 68 foreign representative offices. Russia Today is one of the most famous Russian media in the world, distributing its content in Russian, English, Arabic, French, and Spanish. RT has repeatedly been faced with accusations regarding a lack of objectivity in reporting information (Yablokov, 2015) and the distribution of fake news (MacFarquhar, 2016).

Sampled newsgroups representing private media are owned by RBC (Vkontakte, n.d.-c) and Meduza (Vkontakte, n.d.-b). RBC is also known as RosBusinessConsulting - the largest private Russian media holding. The organization includes a television channel, an information agency, a newspaper, and a magazine, as well as a number of other services. In 2016, the entire top management of RBC was changed following a series of conflicts with the Ministry of Internal Affairs (Meduza, 2016). In 2017, the RBC website became the most quoted online resource (Medialogia, 2018). Meduza is a popular news site in Russia, headquartered in Latvia. This site was launched in 2014 by the former chief editor of the online media Lenta.ru, after her removal from office, which resulted in the voluntary resignation of a significant part of the editorial board (Lenta.ru, 2014). It is considered one of the most independent Russian-language media, due to the fact that it does not fall under restrictions of Roskomnadzor.

None of the presented media specializes solely in hard news, they all have a significant share of soft news.

\subsection{News Items}

For each of the four newsgroups, 200 posts were randomly selected from the whole news dataset for the period from January 17 to March 9, 2018. Some posts were excluded from the sample for two reasons: because they contained not news but, for example, an analytical article or podcast, or because the message of a text may have been so vague that it was impossible to understand it (for instance: "Future is coming", "They say, it's temporary, but it is still frightening").

Vkontakte posts, whose format is used by media outlets, provide users with the following feedback options- 
they could give likes, share content with other users and leave comments. Apart from this, the number of those who have seen a post is recorded, which enables us to calculate the proportion of those who have decided to respond to post content in any of the ways available.

The special features of Vkontakte posts are a highly standardized format and a tendency towards compliance with the principle of an inverted pyramid, which is typical of modern news media, focused on facts (Høyer, 1997). In most cases, the content of a title and a lead allows the presence of relevant news values in posts to be assessed of with a high degree of confidence. Despite the fact that media, in general, use different types of content, not to mention the numbers of communication channels, Vkontakte newsgroups stick to similar formats, which enables us to compare them.

\section{Method}

\subsection{Coding}

To code news items, we used the classification of values developed by Harcup and O'Neill (2016), excluding Shareability, Relevance, and News organization's agenda. The authors of the taxonomy added the property of Shareability but did not provide a clear description for identifying it. Besides this, their definition of it as stories which encourage users to share them and make comments in social media seems to deprive the rest of the values of the opportunity to be shared. This makes this classification less applicable for the purpose of analyzing the users' response in social media. Relevance was excluded due to the fact that almost every news item falls under the definition given by the authors, since almost all the stories that journalists include in the news organization's agenda concern influential or culturally close groups or nations. This category should be measured with a continuous rather, than a dichotomous scale, and news writers, no doubt, are guided by it, ranking the events from the less relevant to the more relevant for their audience. We refrained from using News Organization's Agenda since the presented media did not openly state any special topics, so we decided to exclude this category for the time being.

The coding procedure was a rather complicated task because of several factors: first, the definitions of news values proposed by Harcup and O'Neill (2016) are somewhat vague, therefore to be able to use them, we had to analyze a significant part of the sample; second, correct identification of some news values required a list to be developed including organizations and the people representing them (for instance, The Power elite and Celebrities), as well as this, each coder had to study the news agenda of the period under consideration in order to trace follow-up news correctly. It is plain to see that the coders had to take into account a wide variety of details, as a result of this we decided to employ the methodology of negotiated coding (Campbell, Quincy, Osserman, \& Pedersen, 2013; Garrison, Cleveland-Innes, Koole, \& Kappelman, 2006) which is typically used in qualitative research.

The coding was conducted using the following algorithm: initially, rules were formulated; using them, the coders labelled the whole sample of posts, after which Cohen's kappas were calculated for each news value and the coders discussed their results and changed the coding scheme, after which the coding procedure was repeated. Labelling the whole set of texts by both coders was required because the share of some news values was rather small (for instance, Good News), consequently, it was necessary to process all posts to ensure the reliability of their coding. In our case, it required us to repeat the algorithm three times in order to achieve a high level of inter-coder reliability. The values of Cohen's kappas for the news values at each stage are presented in Table 1.

\subsection{Data Analysis}

To answer RQ1 and RQ3, we implemented multiple linear regression models where the cases are news posts.

Table 1. Cohen's kappas.

\begin{tabular}{lccc}
\hline & \multicolumn{2}{c}{ Cohen's kappa } & Round 3 \\
\hline Exclusivity & Round 1 & Round 2 & 0,98 \\
Bad news & 0,75 & 0,77 & 0,93 \\
Conflict & 0,62 & 0,65 & 0,97 \\
Surprise & 0,68 & 0,77 & 0,95 \\
Audio-visuals & 0,52 & 0,58 & 0,95 \\
Entertainment & 0,80 & 0,80 & 0,97 \\
Drama & 0,81 & 0,83 & 0,97 \\
The power elite & 0,79 & 0,79 & 0,97 \\
Magnitude & 0,77 & 0,77 & 0,95 \\
Celebrity & 0,59 & 0,77 & 0,98 \\
Good news & 0,74 & 0,74 & 0,99 \\
Follow-up & 0,76 & 0,78 & 0,97 \\
\hline
\end{tabular}


Independent variables are news values, each of which is binary. Since all the newsgroups have different average shares of likes, comments and reposts, we used a categorical variable which represented these newsgroups as the control one. Dependent variables are the shares of likes, reposts, and comments from the number of views per post. For the convenience of calculation, these shares were multiplied by 1000 . Since all dependent variables have positive skewness, we decided to apply log transformation to normalize them.

\section{Results}

The most frequent stories in the news agenda in the four media on "Vkontakte" were, on average, those related to previously published news (Figure 1). Approximately the same shares were obtained by the news, containing information about the power elite. The Good news and, oddly enough, those stories which carried audiovisual content in the form of photographs or videos were rarely encountered.

Responding to RQ2, it can be noted that there are few sharp differences in the share of certain news values between private and state online media outlets. The first dissimilarity is apparent in the value of Conflict: the stateowned media are much less likely to publish such stories than the privately-owned media, $X^{2}(1, N=800)=12.01$, $p<.01$. The privately-owned media are more likely to try to entertain readers by posting news containing Drama, $X^{2}(1, N=800)=5.41, p<.05$.

Three out of four online media have one or more news values whose shares are noticeably higher than the rest. In the TASS agenda, Good news occupies much more space, and along with this, audio-visual content is more frequently attached to its news posts. More than a half of the RBC agenda is devoted to influential people and organizations (The power elite); apart from that, this news organization focuses more on events with serious consequences for a large number of people (Magnitude). Meduza entertains its audience most actively (Entertainment $=38 \%$ ), but at the same time, unlike the rest of the media, is not so afraid of scaring its users off with bad news.

It is worth separately noting the unpopularity of bad news revealed in our study, as it disagrees with the famous journalistic guideline "if it bleeds, it leads". One should not exclude the possibility that this result could be generated by some uncertainty in the description of

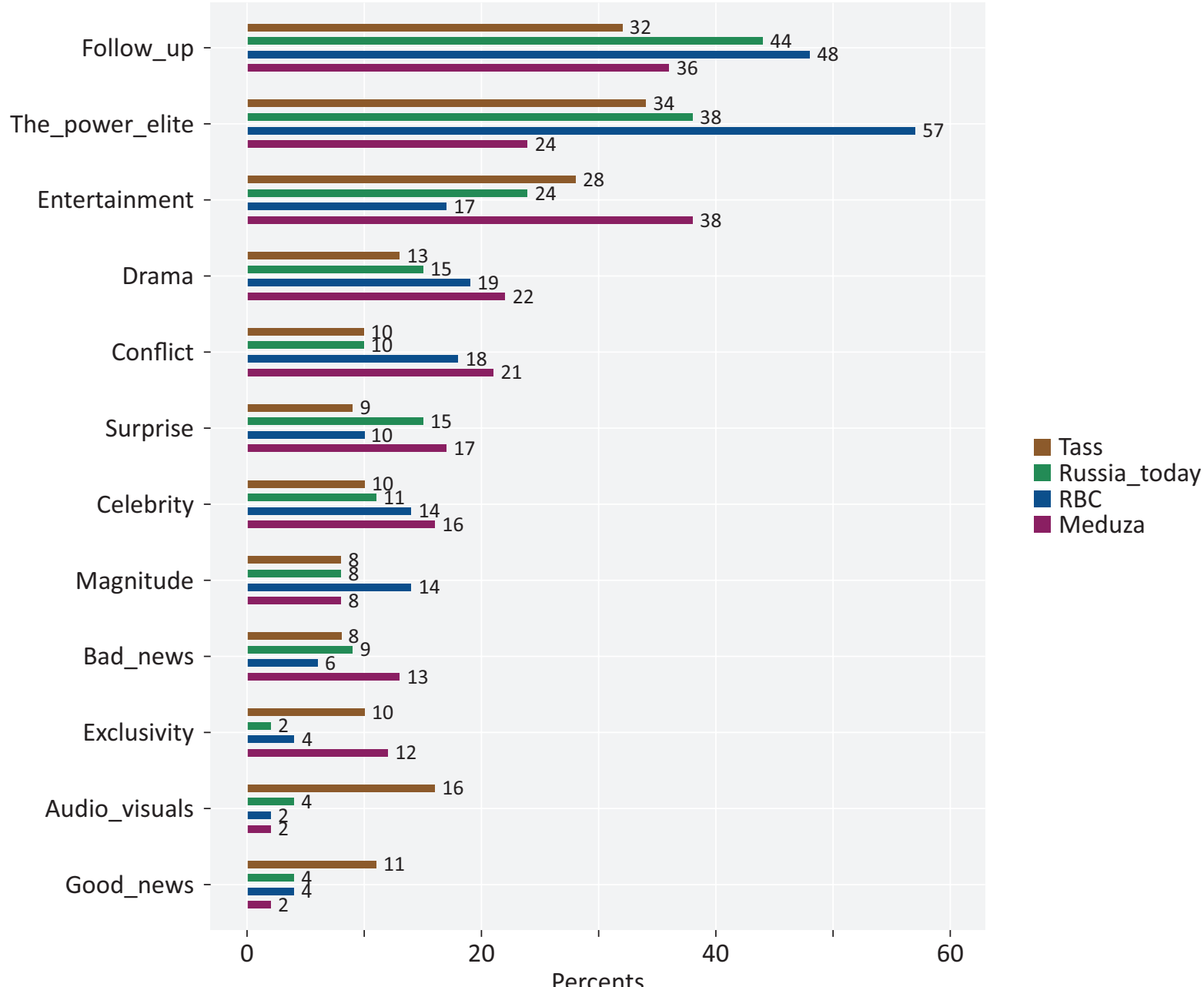

Figure 1. News values distribution. 
what events are covered by Bad news in the Harcup and O'Neill (2016) classification; so, consequently, the subjective perception has affected the labelling of Bad news. Nevertheless, there are some reasons to believe that the media, both for motives related solely to the organizations' policies (for example, pursuing propaganda purposes not to talk about bad things), and due to the fact that Bad news does not gain the expected response from an audience, restricting their shares on the social media platforms.

To answer RQ1, we used multiple linear regression, including all four newsgroups in the sample. This enabled us to find out if there are any dependencies, common to all the media, for various types of response. The results of the regression analysis presented in Table 2 showed both the presence of somewhat expected dependencies and some whose explanation requires additional analysis.

Analyzing the expected results we can note the negative relationship between bad news and the share of likes-obviously, people do not want to give likes to bad events. Conversely, members of newsgroups like good and entertaining news, and furthermore, good news tends to be shared. It can be assumed, that stories about a conflict provoke readers to argue in the comments. The effect of surprise encourages users to leave comments under a post, probably because Vkontakte, unlike Facebook, does not provide the expression of surprise (in the form of a distinct smile) and, apparently, users want to express this feeling publicly. Quite expectedly, users tend to discuss and share important events (Magnitude) with their friends on social networking sites, as well as the exclusive content, provided by newsgroups. Not surprisingly, news describing celebrities or influential people is more intensely commented on by the audience, because, apparently, this is how the personification effect works, encouraging people to discuss other people. The positive relationship between the share of comments and Follow-up stories is also explicable: users have already formed their opinions on these events and seek to voice them. At the same time, the negative dependency between this type of news and the share of likes and reposts is also clear: the audience sees no reason to support and share stories that are already familiar to them.

In the total of the four newsgroups, there was no dependency between the shares of likes, reposts, and comments and news containing Drama. Perhaps, in order to find a relationship between this news value and the public's response, it is necessary to record and analyze some other types of user feedback that are not provided by the social networking site Vkontakte.

To test RQ3, we also used multiple regression, dividing the sample into two types of media. As the number of news values is relatively small, we decided to include in the analysis dependencies with $p$ values $<0.1$. Since the number of cases representing several news values became too small within separate samples (especially Good news, Audio-visuals, and Exclusivity), some dependencies found in the total sample ceased to be significant.

The comparison of the results shown in Tables 3 and 4 revealed only some differences between the audience's reactions to private and state-owned media. Indeed, the readers of Meduza and RBC are less sensitive to bad news: the shares of likes and comments under such posts drops insignificantly in comparison with the average value in the sample. The users of these news groups are not greatly affected by stories about conflicts or celebrities, along with that they are likely to follow unfolding events and, consequently, comment on them more actively.

The regression analysis showed that news with surprising elements encourages the users of state-owned newsgroups to leave more comments, whereas the users of those which are private-owned put more likes to such news. This may reflect the fact that in the first case sur-

Table 2. Multiple regression models testing news values for likes, reposts and comments: All cases.

\begin{tabular}{lccc}
\hline & \multicolumn{2}{c}{ Regression coefficients } & Reposts \\
\hline & Likes & Comments & $0,069^{*}$ \\
\hline Exclusivity & $-0,037$ & $-0,105$. & $-0,003$ \\
Bad news & $-0,175^{* *}$ & $-0,087$ & 0,016 \\
Conflict & 0,024 & $0,090^{*}$ & 0,008 \\
Surprise & $0,100$. & $0,102^{*}$ & $-0,005$ \\
Audio-visuals & $-0,054$ & $-0,101$ & $-0,042$ \\
Entertainment & $0,285^{* * *}$ & 0,004 & $-0,005$ \\
Drama & $-0,023$ & $-0,014$ & 0,011 \\
The power elite & $-0,001$ & $0,097^{* *}$ & $0,085^{* *}$ \\
Magnitude & 0,019 & $0,116^{*}$ & $-0,035$ \\
Celebrity & 0,020 & $0,108^{*}$ & $0,112^{* * *}$ \\
Good news & $0,598^{* * *}$ & 0,019 & $-0,038^{*}$ \\
Follow-up & $-0,059^{*}$ & $0,106^{* *}$ & 0,192 \\
Adjusted $\mathrm{R}^{2}$ & 0,33 & 0,25 & \\
\hline
\end{tabular}

Notes: ${ }^{* *} \mathrm{p}<0.001,{ }^{* *} \mathrm{p}<0.01,{ }^{*} \mathrm{p}<0.05$. Sample size $=800$. Adjusted $\mathrm{R}^{2}=$ explained variance. 
Table 3. Multiple regression models testing news values for likes, reposts and comments: State-owned media.

\begin{tabular}{lccc}
\hline & \multicolumn{2}{c}{ Regression coefficients } \\
\hline & Likes & Comments & Reposts \\
\hline Exclusivity & $-0,037$ & $-0,038$ & $0,125^{* *}$ \\
Bad news & $-0,234^{*}$ & $-0,199^{*}$ & $-0,068$ \\
Conflict & 0,127 & $0,172^{*}$ & $0,044$. \\
Surprise & 0,077 & $0,167^{*}$ & $-0,003$ \\
Audio-visuals & $-0,104$ & $-0,131$. & $-0,011$ \\
Entertainment & $0,321^{* * *}$ & 0,013 & 0,032 \\
Drama & $-0,006$ & 0,015 & 0,001 \\
The power elite & 0,067 & $0,094$. & 0,020 \\
Magnitude & 0,029 & $0,162$. & 0,059 \\
Celebrity & 0,028 & $0,236^{* *}$ & $-0,030$ \\
Good news & $0,670^{* * *}$ & 0,041 & $0,118^{* *}$ \\
Follow-up & $-0,043$ & 0,048 & $-0,014$ \\
Adjusted $R^{2}$ & 0,376 & 0,309 & 0,327 \\
\hline
\end{tabular}

Notes: ${ }^{* *} \mathrm{p}<0.001,{ }^{* *} \mathrm{p}<0.01,{ }^{*} \mathrm{p}<0.05 ., . \mathrm{p}<0.1$. Sample size $=400$. Adjusted $\mathrm{R}^{2}=$ explained variance.

Table 4. Multiple regression models testing news values for likes, reposts and comments: Private-owned media.

\begin{tabular}{lccc}
\hline & \multicolumn{2}{c}{ Regression coefficients } & Reposts \\
\hline Exclusivity & Likes & Comments & 0,026 \\
Bad news & $-0,040$ & $-0,180^{*}$ & 0,060 \\
Conflict & $-0,106$ & $-0,007$ & 0,004 \\
Surprise & $-0,029$ & 0,045 & 0,024 \\
Audio-visuals & $0,133^{*}$ & 0,036 & 0,048 \\
Entertainment & 0,167 & 0,011 & $0,062^{*}$ \\
Drama & $0,275^{* * *}$ & $-0,001$ & $-0,003$ \\
The power elite & $-0,029$ & $-0,029$ & $-0,003$ \\
Magnitude & $-0,066$ & $0,097^{*}$ & $0,112^{* *}$ \\
Celebrity & 0,038 & 0,082 & $-0,027$ \\
Good news & 0,028 & 0,030 & 0,107 \\
Follow-up & $0,429 * *$ & $-0,132$ & $-0,055^{*}$ \\
Adjusted $\mathrm{R}^{2}$ & $-0,062$ & $0,168^{* * *}$ & 0,057 \\
\hline
\end{tabular}

Notes: ${ }^{* *} \mathrm{p}<0.001,{ }^{* *} \mathrm{p}<0.01,{ }^{*} \mathrm{p}<0.05 ., . \mathrm{p}<0.1$. Sample size $=400$. Adjusted $\mathrm{R}^{2}=$ explained variance.

prise is used in a negative context, and in the second-a positive context.

\section{Discussion and Conclusion}

The study showed how news values shape the agenda of popular media in social media in Russia, as well as how their readers (users of the social networking site Vkontakte) react to the presence of certain values in the news. As well as this, the separate analysis of the public's feedback for private and state-owned media discovered that audiences may also be distinguished by the level of interest in a certain news value.

According to Harcup and O'Neill's (2016) news values taxonomy, from one-third to one-half of the news in social media are occupied by Follow-up stories, a similar share covers the events around the power elite, onefifth to one-third contain entertainment content. Surpris- ingly, a rather small proportion of the agenda was devoted to Bad news-only about $10 \%$ in each newsgroup. We revealed an insignificant number of differences between the private and the state-owned media regarding the preferences of certain news values: there is more soft news in the agenda of newsgroups owned by the private media, and the state-owned media newsgroups publish conflict stories much less frequently.

The analysis of the dependencies between the type of news value, presented in the news, and the type of public response generally showed the expected results. Users tend to like and share good news and entertaining news as opposed to bad news. If there are influential or famous people in a news post, it will receive more comments as a result of the personification effect. Media audiences are also keen to share important and exclusive news with their friends on a social networking site. An unexpected discovery was the negative relationship be- 
tween the share of comments and the presence of exclusive content in a post. Perhaps, the novelty of information has such an effect on the users' behaviour.

The results obtained demonstrate that applying news values to reveal the differences in reactions between media audiences is not justified. Despite the fact that we identified some of them, for example, in commenting on bad news or stories with conflicts in newsgroups, which are outlets of state and private-owned media, in relation to the majority of news values, the users' behaviour is similar. Perhaps, for this task, another set of factors may be developed with partial adaptation of news values.

The high complexity of the coding procedure which uses a news values scheme requires a more detailed taxonomy. For instance, it seems reasonable to divide news values into groups as was done in the study dedicated to users' activities around the Ice Bucket Challenge news, where a set of emotions was applied as a separate category of shareworthiness (Kilgo, Lough, \& Riedl, 2017). Monika Bednarek and Helen Caple (2017) developed their own classification of news values, grouping narrowly defined values into wider categories. Unfortunately, the practical application of this scheme in news coding is still complicated, since subcategories are left without clear definition.

The results definitely have limitations imposed by the sample, the chosen classification scheme, and, probably, by our understanding of the news values defined within the chosen conception. The category Drama suggested by Harcup and O'Neill (2016) has caused us considerable difficulties when interpreting the news. We understand that in many respects the intuitive process of news selection restricts its formal definition, and this leads to ambiguity of news value formulations.

We understand that some of the identified dependencies could be false positives, both because of a random error and because of the context of events that were occurring during the period of time investigated. In addition, studying the characteristics of audience interest and reaction is restrained by the available functionality of the social networking site Vkontakte, which those visiting this site can use to leave feedback to a post.

Our study provided empirical evidence of the influence of news values on the behaviour of online media audiences on social networking sites. Since online media are among the main spaces where public opinion is formed and expressed in social media, the results obtained may enhance the methodology of these sociological studies. We hope that this article may stimulate future research into developing a more comprehensive method.

\section{Acknowledgments}

We would like to thank our colleagues from the Faculty of Applied Mathematics and Control Processes and the Center for Sociological and Internet Research of Saint Petersburg State University for guidance and support.

\section{Conflict of Interests}

The authors declare no conflict of interests.

\section{References}

Almgren, S. M., \& Olsson, T. (2015). 'Let's get them involved'...to some extent: Analyzing online news participation. Social Media + Society, 1(2). https://doi. org/10.1177/2056305115621934

Al-Rawi, A. (2017). News values on social media: News organizations' Facebook use. Journalism, 18(7), 871-889.

Armstrong, C. L., \& Gao, F. (2010). Now tweet this: How news organizations use Twitter. Electronic News, 4(4), 218-235.

Bednarek, M., \& Caple, H. (2017). The discourse of news values: How news organizations create newsworthiness. New York, NY: Oxford University Press.

Campbell, J. L., Quincy, C., Osserman, J., \& Pedersen, O. K. (2013). Coding in-depth semistructured interviews: Problems of unitization and intercoder reliability and agreement. Sociological Methods \& Research, 42(3), 294-320.

Cohen, R., \& Ruths, D. (2013). Classifying political orientation on Twitter: It's not easy! In Proceedings of the seventh international $A A A$ l conference on weblogs and social media (pp. 91-99). Palo Alto, CA: AAAI Press.

Costera Meijer, I., \& Kormelink, T. (2015). Checking, sharing, clicking and linking: changing patterns of news use between 2004 and 2014. Digital Journalism, 3(5), 664-679.

DiGrazia, J., McKelvey, K., Bollen, J., \& Rojas, F. (2013). More tweets, more votes: Social media as a quantitative indicator of political behavior. PloS One, 8(11). https://doi.org/10.1371/journal.pone.0079449

Dominick, J. (1993). The dynamics of mass communication. New York, NY: McGraw-Hill Education.

Field, A., Kliger, D., Wintner, S., Pan, J., Jurafsky, D., \& Tsvetkov, Y. (2018). Framing and agenda-setting in Russian news: A computational analysis of intricate political strategies. arXiv.org. Retrieved from arXiv:1808.09386

Galtung, J., \& Ruge, M. H. (1965). The structure of foreign news: The presentation of the Congo, Cuba and Cyprus crises in four Norwegian newspapers. Journal of Peace Research, 2(1), 64-90.

García-Perdomo, V., Salaverría, R., Kilgo, D. K., \& Harlow, S. (2018). To share or not to share: The influence of news values and topics on popular social media content in the United States, Brazil, and Argentina. Journalism Studies, 19(8), 1180-1201.

Garrison, D. R., Cleveland-Innes, M., Koole, M., \& Kappelman, J. (2006). Revisiting methodological issues in transcript analysis: Negotiated coding and reliability. The Internet and Higher Education, 9(1), 1-8.

Golding, P., \& Elliott, P. R. C. (1979). Making the news. 
London: Longman.

Hanitzsch, T., Folker, H., \& Corinna, L. (2016). Setting the agenda, influencing public opinion and advocating for social change: Determinants of journalistic interventionism in 21 countries. Journalism Studies, 17(1), 1-20.

Hansen, L. K., Arvidsson, A., Nielsen, F. Å., Colleoni, E., \& Etter, M. (2011). Good friends, bad news-affect and virality in Twitter. In J. J. Park, L. T. Yang, \& C. Lee (Eds.), Future information technology (pp. 34-43). Berlin: Springer.

Harcup, T., \& O'Neill, D. (2016). What is news? News values revisited (again). Journalism Studies, 18(12), 1470-1488.

Høyer, S. (1997). Why study journalistic genres? Journalism at the crossroads: Perspectives on research. Tartu: Tartu University press.

Judina, D., \& Platonov, K. (2018). Measuring agenda setting and public concern in Russian social media. In International conference on internet science (pp. 211-225). Cham: Springer.

Kilgo, D. K., Lough, K., \& Riedl, M. J. (2017). Emotional appeals and news values as factors of shareworthiness in Ice Bucket Challenge coverage. Digital Journalism, 2017(1/20). https://doi.org/10.1080/21670811. 2017.1387501

Ksiazek, T. B., Peer, L., \& Lessard, K. (2016). User engagement with online news: Conceptualizing interactivity and exploring the relationship between online news videos and user comments. New Media \& Society, 18(3), 502-520.

Lee, A. M., \& Chyi, H. I. (2014). When newsworthy is not noteworthy: Examining the value of news from the audience's perspective. Journalism Studies, 15(6), 807-820.

Lee, C. S., \& Ma, L. (2012). News sharing in social media: The effect of gratifications and prior experience. Computers in Human Behavior, 28(2), 331-339.

Lenta.ru (2014). Iz "Lenty.ru" uvolilis' 39 chelovek [39 people resigned from "Lenta.ru"]. Lenta.ru. Retrieved from https://lenta.ru/news/2014/03/13/ lentaru/

Live Internet. (n.d.). Rating. Live Internet. Retrieved from https://www.liveinternet.ru/rating/ru/

Lukyanova, G. (2018). Framing in Russian TV news: How to shape reality? In Current issues of linguistics and didactics: The interdisciplinary approach in humanities and social sciences, 50,1-6. https://doi.org/10.1051/ shsconf/20185001098

MacFarquhar, N. (2016) A powerful russian weapon: The spread of false stories. New York Times. Retrieved from https://www.nytimes.com/2016/08/29/world/ europe/russia-sweden-disinformation.html

McGregor, J. (2002). Restating news values: Contemporary criteria for selecting the news. In Refereed articles from the proceedings of the ANZCA 2002 conference: Communication: Reconstructed for the 21st century. Coolangatta: Bond University. Re- trieved from https://www.researchgate.net/profile/ Judy_Mcgregor/publication/228774915_Restating_ news_values_Contemporary_criteria_for_selecting_ the_news/links/544413e90cf2a6a049ab07b1/ Restating-news-values-Contemporary-criteria-forselecting-the-news.pdf

Medialogia. (2018). Top-30 samyh citiruemyh Internetresursov: 2017 god [Top 30 most cited Internet resources: 2017]. Medialogia. Retrieved from http:// www.mlg.ru/ratings/media/federal/5766

Meduza. (2016). Razgrom RBK. Korotko. Glavnoe, chto nuzhno znat' ob uvol'nenii rukovoditelej luchshej redakcii v Rossii [The defeat of RBC. In short, all you need to know about the dismissal of the best editors in Russia]. Meduza. Retrieved from https://meduza. io/feature/2016/05/13/razgrom-rbk-korotko

Mislove, A., Lehmann, S., Ahn, Y. Y., Onnela, J. P., \& Rosenquist, J. N. (2011). Understanding the demographics of Twitter users. In ICWSM '11: 5th international AAAl conference on weblogs and social media (pp. 554-557). San Francisco, CA: AAAI Press.

$\emptyset$ rmen, J. (2018). From consumer demand to user engagement: Comparing the popularity and virality of election coverage on the Internet. The International Journal of Press/Politics, 24(1), 49-68. https://doi. org/10.1177/1940161218809160

Preoțiuc-Pietro, D., Liu, Y., Hopkins, D., \& Ungar, L. (2017). Beyond binary labels: Political ideology prediction of Twitter users. In Proceedings of the 55th annual meeting of the Association for Computational Linguistics (Vol. 1, pp. 729-740). Stroudsburg, PA: Association for Computational Linguistics.

Reinemann, C., Stanyer, J., Scherr, S., \& Legnante, G. (2012). Hard and soft news: A review of concepts, operationalizations and key findings. Journalism, 13(2), 221-239.

Smoliarova, A. S., Gromova, T. M., \& Pavlushkina, N. A. (2018). Emotional stimuli in social media user behavior: Emoji reactions on a news media facebook page. In S. Bodrunova (Ed.), International conference on internet science (pp. 242-256). Cham: Springer.

Stieglitz, S., \& Dang-Xuan, L. (2013). Emotions and information diffusion in social media: Sentiment of microblogs and sharing behavior. Journal of Management Information Systems, 29(4), 217-248.

Trilling, D., Tolochko, P., \& Burscher, B. (2017). From newsworthiness to shareworthiness: How to predict news sharing based on article characteristics. Journalism \& Mass Communication Quarterly, 94(1), 38-60.

Tsagkias, M., Weerkamp, W., \& De Rijke, M. (2009). Predicting the volume of comments on online news stories. In Proceedings of the 18th ACM conference on information and knowledge management ( $\mathrm{pp}$. 1765-1768). New York, NY: ACM.

VCIOM. (2018). VCIOM-Sputnik database. VCIOM. Retrieved from https://wciom.ru/trzh/print_q.php?s_ $i d=83 \& q \_i d=5923 \&$ date $=01.04 .2018$ 
Vkontakte. (n.d.-a). Vkontakte. Retrieved from https:// vk.com/catalog.php

Vkontakte. (n.d.-b). Vkontakte. Retrieved from https:// vk.com/meduzaproject

Vkontakte. (n.d.-c). Vkontakte. Retrieved from https:// vk.com/rbc

Vkontakte. (n.d.-d). Vkontakte. Retrieved from https:// vk.com/rt_russian

Vkontakte. (n.d.-e). Vkontakte. Retrieved from https:// vk.com/tassagency

Yablokov, I. (2015). Conspiracy theories as a Russian public diplomacy tool: The case of Russia Today (RT). Politics, 35(3/4), 301-315.

Ziegele, M., Breiner, T., \& Quiring, O. (2014). What creates interactivity in online news discussions? An exploratory analysis of discussion factors in user comments on news items. Journal of Communication, 64(6), 1111-1138.

\section{About the Authors}

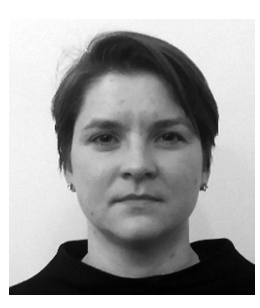

Darja Judina is a Specialist in the Center for Sociological and Internet Research, Research Park, Saint Petersburg State University, Russia. Her research interests include public opinion, social media, media audiences, and online communities. She has experience in electoral studies and surveys of state policies.

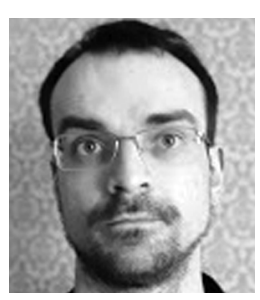

Konstantin Platonov is a Specialist in the Center for Sociological and Internet Research, Research Park, Saint Petersburg State University, Russia, and a Candidate of Sociological Sciences (PhD equivalent). His research focuses on the representation of different social issues and challenges in social media content. Field of scholarly endeavour: digital protest, online communities, public opinion, opinion mining, research methodologies on social networking sites, and social ecology. 